\title{
Metastatic Ovarian Carcinoma
}

National Cancer Institute

\section{Source}

National Cancer Institute. Metastatic Ovarian Carcinoma. NCI Thesaurus. Code C156064.

A carcinoma that arises from the ovary and has metastasized to another anatomic site. 